13,05

\title{
Фоторезистивный детектор циркулярно-поляризованного излучения на основе МДП-структуры со слоем CoPt
}

\author{
() А.В. Кудрин ${ }^{1,2}$, М.В. Дорохин ${ }^{1,2}$, А.В. Здоровейщев ${ }^{1,2}$, П.Б. Дёмина ${ }^{1}$, О.В. Вихрова ${ }^{1}$, \\ И.Л. Калентьева ${ }^{1}$, М.В. Ведь ${ }^{1,2}$ \\ ${ }^{1}$ Научно-исследовательский физико-технический институт \\ Нижегородского государственного университета им. Н.И. Лобачевского, \\ Нижний Новгород, Россия \\ ${ }^{2}$ Нижегородский государственный университет им. Н.И. Лобачевского, \\ Нижний Новгород, Россия \\ E-mail: kudrin@nifti.unn.ru
}

Создан фоторезистивный детектор циркулярно-поляризованного излучения на основе структуры металлдиэлектрик-полупроводник $\mathrm{CoPt} /\left(\mathrm{Al}_{2} \mathrm{O}_{3} / \mathrm{SiO}_{2} / \mathrm{Al}_{2} \mathrm{O}_{3}\right) / \mathrm{InGaAs} / \mathrm{GaAs}$. Эффективность детектирования циркулярно-поляризованного излучения составляет $0.75 \%$ при комнатной температуре. Работа детектора основана на проявлении эффекта магнитоциркулярного дихроизма в слое $\mathrm{CoPt}$ - зависимости коэффициента пропускания CoPt от знака циркулярной поляризации света и намагниченности.

Работа выполнена в рамках реализации государственного задания (проект № 8.1751.2017/ПЧ Минобрнауки России), при поддержке РФФИ (гранты 17-37-80008 мол_эв_а, 16-07-01102_а) и гранта (МК-8221.2016.2) Президента Российской Федерации.

DOI: 10.21883/FTT.2017.11.45062.17k

\section{1. Введение}

Детекторы циркулярно-поляризованного излучения (ЦПИ), демонстрирующие связь электрической величины (тока или напряжения) со знаком и степенью поляризации света, могут быть использованы в системах оптической передачи информации. В частности, такие детекторы могут быть частью системы оптической передачи данных в электронно-оптических интегральных схемах. Основным направлением по созданию детекторов циркулярно-поляризованного излучения является использование систем „ферромагнитный металл/полупроводниковая структура“. Вариантами таких систем являются структуры металл/полупроводник с барьером Шоттки [1], металл/туннельный диэлектрический слой/полупроводник [2], металл/p-i-nфотодиод $[3,4]$. В качестве ферромагнитных металлов используются слои $\mathrm{Fe}, \mathrm{NiFe}, \mathrm{Co}, \mathrm{CoFeB}, \mathrm{CoFeSi}$. Работа таких детекторов основана на эффекте спиновой фильтрации фотовозбужденных носителей заряда на интерфейсе ферромагнетик/полупроводник. Облучение полупроводниковой области циркулярно-поляризованным светом приводит к возникновению в ней поляризованных по спину носителей заряда. Для спин-поляризованных носителей заряда различаются вероятности прохождения через барьер ферромагнетик/полупроводник, что приводит к зависимости величины фототока через структуру от направления циркулярной поляризации света или намагниченности ферромагнитного контакта. Для функционирования указанных приборов необходимо протекание тока перпендикулярно слоям структуры. Нами предложен альтернативный вариант детектора циркулярнополяризованного излучения с протеканием тока вдоль плоскости структуры и основанного на использовании эффекта магнитоциркулярного дихроизма (МЦД).

\section{2. Методика эксперимента}

Магнитоциркулярный дихроизм выражается в различии коэффициента отражения (и пропускания) в ферромагнитном материале для лево- и правоциркулярнополяризованных компонент света. Изготовленный детектор функционирует за счет комбинации эффектов МЦД в ферромагнитном слое $\mathrm{CoPt}$ и фотопроводимости в слое InGaAs. На подложке $i$-GaAs методом MOC-гидридной эпитаксии при температуре $600^{\circ} \mathrm{C}$ были выращены буферный слой $\mathrm{GaAs}$ (толщиной $\approx 100 \mathrm{~nm}$ ) и слой InGaAs (толщиной $\approx 200 \mathrm{~nm}$ ). Содержание индия в слое $\operatorname{In}_{x} \mathrm{Ga}_{1-x}$ As составляло $x_{\text {In }}=0.11 \%$. Легирование слоев в процессе роста не проводилось. На поверхности полупроводниковой структуры методом электронно-лучевого испарения (ЭЛИ) создавался слой комбинированного диэлектрика $\mathrm{Al}_{2} \mathrm{O}_{3} / \mathrm{SiO}_{2} / \mathrm{Al}_{2} \mathrm{O}_{3}$ общей толщиной $170 \mathrm{~nm}$. Далее также методом ЭЛИ на диэлектрик наносился слой $\mathrm{Co}_{0.45} \mathrm{Pt}_{0.55}$ толщиной $8 \mathrm{~nm}$. Назначение диэлектрика заключается в электрической изоляции относительно высокоомного слоя InGaAs от более проводящего слоя CoPt при исследовании планарной фотопроводимости структуры. К слою InGaAs создавались In омические контакты. Таким образом, формировалась структура фоторезистивного элемента, которая демонстрировала $p$-тип проводимости и имела величину темнового слоевого сопротивления $89 \mathrm{k} \Omega^{-2}$. На рис. 1 представлено схематическое изображение структуры. Исследование фотопроводимости проводилось при освещении структуры через слой CoPt. B каче- 


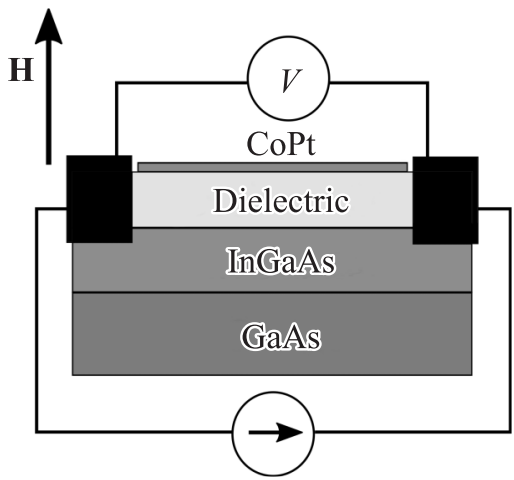

Рис. 1. Схематическое изображение фоторезистора для детектирования циркулярно-поляризованного излучения.

стве источника света использовалась галогенная лампа накаливания, излучение от которой пропускалось через монохроматор. Выходящий из монохроматора свет проходил через опто-механический модулятор, далее через линейный поляризатор и затем через четвертьволновую $(\lambda / 4)$ пластину. Положение четвертьволновой пластины определяло направление циркулярной поляризации света, падающего на фоторезистор перпендикулярно поверхности CoPt. Структура помещалась в магнитное поле напряженностью до \pm 1900 Ое, ориентированное перпендикулярно плоскости. При каждом значении магнитного поля проводилось поочередное освещение структуры лево- $(L)$ и право- $(R)$ 98\% поляризованным светом. Эффективность детектирования ЦПИ определялась следующим образом: $\left(V_{L}-V_{R}\right) /\left(V_{L}+V_{R}\right)$, где $V_{L}$ и $V_{R}$ падение напряжения на омических контактах структуры при освещении светом соответствующей поляризации. Величина напряжения на омических контактах регистрировалась фазочувствительным вольтметром, работающим на частоте опто-механического модулятора $(170 \mathrm{~Hz})$. Через слой InGaAs пропускался постоянный ток величиной $10 \mu \mathrm{A}$. Спектры фотопроводимости $S(\lambda)$ были получены в диапазоне $0.8-1.1 \mu \mathrm{m}$ без использования линейного поляризатора и пластины $\lambda / 4$. Величина $S(\lambda)$ определялась как спектральная зависимость возникающего на контактах напряжения $V(\lambda)$, отнесенного к интенсивности излучения лампы $I_{L}(\lambda)$. Фотолюминесценция слоя InGaAs получена при возбуждении через слой диэлектрика лазером с длиной волны $450 \mathrm{~nm}$. Спектральные зависимости коэффициента отражения от слоя CoPt в диапазоне $0.7-1.3 \mu \mathrm{m}$ были записаны с использованием спектрофотометра Varian Cary 6000i. Магнитополевые зависимости намагниченности $M(H)$ структуры получены с использованием магнетометра переменного градиента силы в диапазоне напряженности внешнего магнитного поля \pm 1700 Ое. Для оценки величины магнитоциркулярного дихроизма в слое $\mathrm{CoPt}$ была получена структура, представляющая собой аналогичный слой $\mathrm{CoPt}$, нанесенный непосредственно на GaAs-подложку. Магнитополевая зависимость величины магнитоциркулярного дихроизма в слое $\mathrm{CoPt}$ исследо- валась путем пропускания через структуру $\mathrm{CoPt} / \mathrm{GaAs}$ неполяризованного света с длиной волны $920 \mathrm{~nm}$. Структура $\mathrm{CoPt} / \mathrm{GaAs}$ помещалась в магнитное поле (ориентированное перпендикулярно плоскости). Свет, прошедший через структуру $\mathrm{CoPt} / \mathrm{GaAs}$, приобретал частичную циркулярную поляризацию, величина которой определялась с использованием четвертьволновой пластины и линейного поляризатора. Все исследования проведены при комнатной температуре.

\section{3. Экспериментальные результаты}

На рис. 2 кривой 1 представлен спектр фотопроводимости $S(\lambda)$ при облучении структуры через слой диэлектрика. Спектр $S(\lambda)$ для исходной структуры без диэлектрика выглядит аналогично. На спектре присутствует ярко выраженный длинноволновый спад, связанный с фундаментальным краем поглощения $\left(E_{g}\right)$ слоя InGaAs. Длинноволновый край поглощения, определенный по критерию Мосса из зависимости 1 , соответствует длине волны $\approx 1 \mu \mathrm{m}$. Эта величина близка к положению пика фотолюминесценции $0.98 \mu \mathrm{m}$ (кривая 3 на рис. 3). Полученные значения хорошо согласуются с величиной ширины запрещенной зоны $E_{g}(1.26 \mathrm{eV}$ $(0.984 \mu \mathrm{m}))$ для твердого раствора $\operatorname{In}_{0.11} \mathrm{Ga}_{0.89} \mathrm{As}$. На длине волны $\approx 0.9 \mu \mathrm{m}$ кривая 1 содержит характерный для фотопроводимости коротковолновый спад. Спектр 2 на рис. 2 соответствует $S(\lambda)$ при облучении структуры через слой CoPt. Вид спектра $S(\lambda)$ в этом случае качественно совпадает со спектром при облучении структуры через диэлектрик, следовательно, спектр поглощения CoPt в исследуемом диапазоне не имеет значительных особенностей. Это согласуется со слабой спектральной зависимостью коэффициента отражения для слоя $\mathrm{CoPt}$, представленного на вставке к рис. 2.

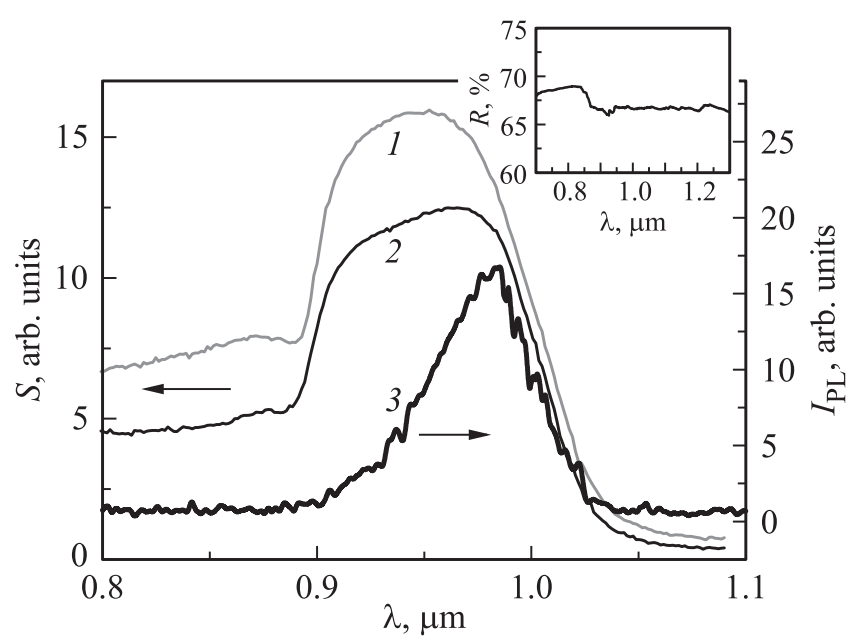

Рис. 2. Спектральные зависимости фотопроводимости при облучении структуры через слой диэлектрика (кривая 1) и через слой $\mathrm{CoPt}$ (кривая 2). Зависимость 3 - спектр фотолюминесценции слоя InGaAs. На вставке приведена спектральная зависимость коэффициента отражения для слоя CoPt. 


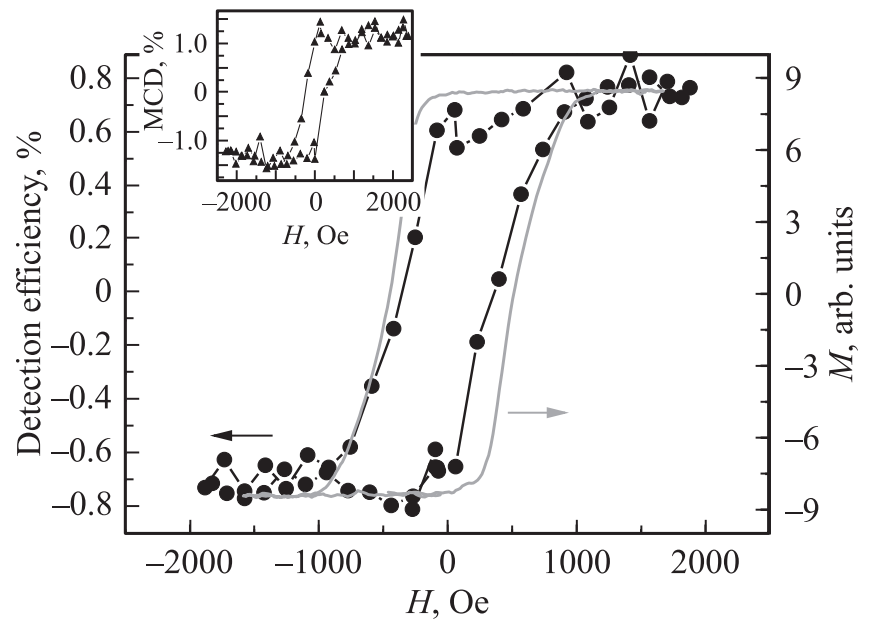

Рис. 3. Магнитополевая зависимость намагниченности структуры (непрерывная линия) и эффективность детектирования циркулярно-поляризованного света (символы). На вставке представлена магнитополевая зависимость величины магнитоциркулярного дихроизма (МСД) в слое $\mathrm{CoPt}$, нанесенном на GaAs подложку.

На рис. 3 непрерывной линией представлена магнитополевая зависимость намагниченности исследуемого фоторезистора при ориентации внешнего магнитного поля перпендикулярно плоскости структуры. Очевидно, что зависимость $M(H)$ соответствует магнитополевой зависимости намагниченности слоя CoPt. Слои $\mathrm{CoPt}$, полученные используемым методом ЭЛИ, обладают ярко выраженной перпендикулярной магнитной анизотропией [5]. На рис. 3 символами представлена зависимость эффективности детектирования циркулярнополяризованного излучения от величины внешнего магнитного поля при комнатной температуре для длины волны падающего излучения $0.96 \mu \mathrm{m}$ (на максимуме спектральной зависимости фотопроводимости (рис. 2, кривая 2)). На вставке к рис. 3 представлена магнитополевая зависимость величины магнитоциркулярного дихроизма в слое $\mathrm{CoPt}$, нанесенном на GaAs-подложку. Вид зависимости эффективности детектирования ЦПИ от магнитного поля совпадает с видом магнитополевой зависимости намагниченности структуры и с видом магнитополевой зависимости магнитоциркулярного дихроизма для структуры CoPt/GaAs. Наибольшая величина эффективности детектирования составляет $\approx 0.75 \%$ и соответствует выходу намагниченности слоя CoPt на насыщение. Величина эффективности детектирования согласуется с наблюдаемой величиной магнитоциркулярного дихроизма для структуры $\mathrm{CoPt} / \mathrm{GaAs}(\approx 1.2 \%$, вставка к рис. 3). Наличие эффекта магнитоциркулярного дихроизма в слое $\mathrm{CoPt}$ приводит к зависимости коэффициентов отражения и пропускания слоя CoPt от направления циркулярной поляризации света и намагниченности слоя (определяемой внешним магнитным полем). Результатом этого является различие в количестве фотовозбужденных носителей в слое InGaAs, что приводит к различию в сопротивлении слоя InGaAs и соответственно в регистрируемом значении напряжения. Обращает на себя внимание, что благодаря остаточной намагниченности $\mathrm{CoPt}$, равной по величине намагниченности насыщения, эффективность детектирования левои правоциркулярно-поляризованных компонент света сохраняет свое максимальное значение и в отсутствии внешнего магнитного поля.

Величина эффективности детектирования ЦПИ может быть повышена путем увеличения толщины слоя $\mathrm{CoPt}$, поскольку величина МЦД, определяющая эффективность детектирования, пропорциональна толщине поглощающего магнитного слоя. В дальнейшем планируется исследование зависимости величины эффективности детектирования циркулярно-поляризованного излучения от толщины ферромагнитного слоя, его типа (CoPt, $\mathrm{CoPd}, \mathrm{CoFe})$, длины волны излучения.

\section{4. Заключение}

С использованием методов МОС-гидридной эпитаксии и электронно-лучевого испарения в вакууме получена структура $\mathrm{CoPt} /\left(\mathrm{Al}_{2} \mathrm{O}_{3} / \mathrm{SiO}_{2} / \mathrm{Al}_{2} \mathrm{O}_{3}\right) / \mathrm{InGaAs} / i$-GaAs, являющаяся детектором циркулярно-поляризованного излучения. Детектор функционирует на основе комбинации эффектов фотопроводимости и магнитоциркулярного дихроизма. Эффективность детектирования циркулярнополяризованного излучения составляет $\approx 0.75 \%$ при комнатной температуре, в том числе при отсутствии внешнего магнитного поля, благодаря сохранению остаточной намагниченности слоя $\mathrm{CoPt}$.

Авторы выражают благодарность Б.Н. Звонкову за выращивание полупроводниковой части структуры.

\section{Список литературы}

[1] S.T. Ruggiero, A. Williams, C.E. Tanner, S. Potashnik, J. Moreland, W.H. Rippard. Appl. Phys. Lett. 82, 4599 (2003).

[2] Y.J. Park, M.C. Hickey, M.J. Van Veenhuizen, J. Chang, D. Heiman, C.H. Perry, J.S. Moodera. J. Phys.: Condens. Matter. 23, 116002 (2011).

[3] R. Farshchi, M. Ramsteiner, J. Herfort, A. Tahraoui, H.T. Grahn. Appl. Phys. Lett. 98, 162508 (2011).

[4] P. Renucci, V.G. Truong, H. Jaffres, L. Lombez, P.H. Binh, T. Amand, J.M. George, X. Marie. Phys. Rev. B 82, 195317 (2010).

[5] А.В. Здоровейщев, М.В. Дорохин, О.В. Вихрова, П.Б. Демина, А.В. Кудрин, А.Г. Темирязев, М.П. Темирязева. ФТТ 58, 2186 (2016).

Публикащия материалов Симпозиума завершена. 